\title{
Development of a Stable Cell Line, Overexpressing Human T-cell Immunoglobulin Mucin 1
}

\author{
Mina Ebrahimi 1,2,3, Tohid Kazemi 2, Mazdak Ganjalikhani-hakemi 4,*, Jafar Majidi 2, Hossein khanah- \\ mad 5,**, Ilnaz Rahimmanesh 5, Vida Homayouni ${ }^{4}$, Shirin Kohpayeh 4 \\ ${ }^{1}$ Immunology Research Center, Tabriz University of Medical Sciences, Tabriz, Iran \\ ${ }^{2}$ Department of Immunology, Faculty of Medicine, Tabriz University of Medical Sciences, Tabriz, Iran \\ ${ }^{3}$ Tabriz University of Medical Sciences, Tabriz, Iran \\ ${ }^{4}$ Department of Immunology, Faculty of Medicine, Isfahan University of Medical Sciences, Isfahan, Iran \\ ${ }^{5}$ Department of Genetic and Molecular Biology, Faculty of Medicine, Isfahan University of Medical Sciences, Isfahan, Iran

\begin{abstract}
*Corresponding author: Mazdak Ganjalikhani-hakemi, Department of Immunology, Faculty of Medicine, Isfahan University of Medical Sciences, Isfahan, Iran. Tel: +98-3137929082, Fax: +98-3137929031, E-mail: mghakemi@med.mui.ac.ir

${ }^{* *}$ Co-Corresponding author: Hossein Khanahmad, Department of Genetic and Molecular Biology, Faculty of Medicine, Isfahan University of Medical Sciences. Isfahan, Iran. Tel: +98-3137929087, Fax: +98-3136688597, E-mail: khanahmad@med.mui.ac.ir
\end{abstract}

Received: September 19, 2015; Revised: November 12, 2015; Accepted: November 24, 2015

Background: Recent researches have demonstrated that human T-cell immunoglobulin mucin 1 (TIM-1) glycoprotein plays important roles in regulation of autoimmune and allergic diseases, as well as in tumor immunity and response to viral infections. Therefore, targeting TIM-1 could be a potential therapeutic approach against such diseases.

Objectives: In this study, we aimed to express TIM-1 protein on Human Embryonic kidney (HEK) 293T cell line in order to have an available source of the TIM-1 antigen.

Materials and Methods: The cDNA was synthesized after RNA extraction from peripheral blood mononuclear cells (PBMC) and TIM-1 cDNA was amplified by PCR with specific primers. The PCR product was cloned in pcDNA $^{\mathrm{TM}} 3.1$ /Hygro $(+)$ and transformed in Escherichia coli TOP 10 F'. After cloning, authenticity of DNA sequence was checked and expressed in HEK 293T cells. Finally, expression of TIM-1 was analyzed by flow cytometry and real-time PCR.

Results: The result of DNA sequencing demonstrated correctness of TIM-1 DNA sequence. The flow cytometry results indicated that TIM-1 was expressed in about 90\% of transfected HEK 293T cells. The real-time PCR analysis showed TIM-1 mRNA expression increased 195-fold in transfected cells compared with un-transfected cells.

Conclusions: Findings of present study demonstrated the successful cloning and expression of TIM-1 on HEK 293T cells. These cells could be used as an immunogenic source for production of specific monoclonal antibodies, nanobodies and aptamers against human TIM-1.

Keywords: Cloning; Gene expression; HEK 293T; Immunogenic source; TIM-1

\section{Background}

TIM-1 is a type I membrane glycoprotein expressed on wide variety of cells consisted of $\mathrm{T}$ helper (Th) cells, B cells, mast cells, macrophages and kidney proximal tubular epithelial cells $(1,2)$. TIM-1, also known as hepatitis A virus cellular receptor-1 (HAVCR-1) and kidney injury molecule-1 (KIM-1), is considerably upregulated in proximal tubular epithelial cells of kidney following ischemic and toxic injury (3).

Human TIM-1 gene is located on 5q32.2 locus, which is a region linked with susceptibility to asthma and allergy, and also is highly polymorphic among TIM gene family members $(4,5)$. Structurally, TIM-1 include an $\mathrm{NH}_{2}$-terminal IgV-like domain with an $\mathrm{N}$ linked glycosylation site, a mucin domain containing many $O$-linked glycosylation sites, a transmembrane domain, and a $\mathrm{COOH}$-terminal short cytoplasmic domain (6).

TIM-1 protein as a co-stimulatory molecule regulates the expansion and effector functions of $\mathrm{T}$ helper 
cells, particularly Th-2 immune responses $(7,8)$. Thus, associations between TIM-1 and allergic diseases are evident that makes it a major worldwide health issue (5). Moreover, TIM-1 plays critical role in Th-1 and Th-17 cell homing into the central nervous system (CNS). Thus, TIM-1 might be an important tool to achieve selective tissue homing of T cells in neurodegenerative disorders like multiple sclerosis (MS) (9). TIM-1 also regulates responses to viral infections and homeostasis of tumor microenvironment $(2,10)$. TIM1 as a phosphatidylserine receptor on the surface of antigen-presenting cells helps in the detection and removal of apoptotic cells $(2,11)$. Filoviruses, ebolavirus, alphaviruses and baculoviruses use TIM-1 as a receptor for their entry to host cells (12-14). Phosphatidylserine on the viral envelope through interaction with TIM-1 enhances infection by these viruses $(10,15)$.

Therefore, interference with TIM-1 signaling, stimulating or blocking TIM-1 activity offers a novel approach for potential treatments for $\mathrm{T}$ cell-mediated diseases $(9,16)$. For example, blocking TIM-1 would inhibit Th-2 proliferation and cytokine production in allergic diseases (7). Also, blocking TIM-1 might be useful for preventing entry of Th1 and Th17 cells to CNS in order to help for treatment of multiple sclerosis (9).

\section{Objectives}

Anti-human monoclonal antibody, nanobody and aptamer could be considered as novel therapeutic agents for manipulation of TIM-1 associated immunedisregulations. Producing such agents requires stable source over-expression of TIM-1 antigen on a suitable cell line; not only for having an available source of the antigen, but also to achieve proper folding in TIM-1 protein structure. Hence, we aimed to produce a human TIM-1 expressing cell line using HEK 293T cells.

\section{Materials and Methods}

\subsection{Cells and Bacteria}

HEK 293T cells were purchased from Pasteur Institute of Iran and cultured in DMEM (SigmaAldrich, St., MO, USA) medium supplemented with $1 \%$ (w/v) penicillin/streptomycin (Gibco BRL, Karlsruhe, Germany) and 10\% FBS (Sigma-Aldrich, St., MO, USA) in $5 \% \mathrm{CO}_{2}$ at $37^{\circ} \mathrm{C}$. E. coli TOP $10 \mathrm{~F}$ ' was purchased from Pasteur Institute of Iran and cultured in Luria Bertani (LB) culture medium (SigmaAldrich, St., MO, USA) containing $100 \mu \mathrm{g} . \mathrm{mL}^{-1}$ tetracycline (Sigma-Aldrich, St., MO, USA).

\subsection{PBMC Isolation}

PBMC were isolated from heparinized whole blood samples using gradient centrifugation in Ficoll-Paque solution according to its manufacturer's instruction (Sigma-Aldrich, St., MO, USA).

\subsection{RNA Extraction and cDNA Synthesis}

Total RNA was extracted from PBMC using RNX kit (CinnaGen, Inc, Iran) based on the manufacturer's protocol. Using spectrophotometry and electrophoresis, quantity and quality of the extracted RNA were measured. The extracted RNAs were treated with DNase I (Thermo Fisher Scientific, Inc., MA, USA) and cleaned up with DNA extraction kit (Bioneer Inc., Seoul, South Korea) according to the manufacturer's instruction. cDNA was synthesized from $1 \mu \mathrm{g}$ of the total RNA using first strand cDNA synthesis kit (Thermo Fisher Scientific, Inc., MA, USA) as instructed by the manufacturer.

\subsection{TIM-1 Amplification}

PCR was carried out on the cDNA for specific amplification of TIM-1 using designed specific primer: TIM-1-forward containing NheI restriction site

Table 1. Oligonucleotide primers using in PCR

\begin{tabular}{lccc}
\hline Name & Sequences (5'-3') & Length (bp) & Tm $\left({ }^{\circ} \mathbf{C}\right)$ \\
\hline TIM-1 & Forward: GCTAGCATGCATCCTCAAGTGGTC & 24 & 63.8 \\
& Reverse: CTCGAGTTAGTCCGTGGCATAAAG & 24 & 61.2 \\
pcDNA & Forward: ACTAGAGAACCCACTGCTTACTG & 23 & 60.6 \\
& Reverse: ATGGCTGGCAACTAGAAGG & 19 & 56.7 \\
\multirow{2}{*}{ RTIM } & Forward: ACATAGTCTACTGACGGCCAATACC & 25 & 61.9 \\
& Reverse: CTCGAGTTAGTCCGTGGCATAAAGAC & 26 & 63.2 \\
\multirow{3}{*}{-actin } & Forward: TTCGAGCAAGAGATGGCCA & 19 & 59 \\
& Reverse: CACAGGACTCCATGCCCAG & 19 & 60 \\
\hline
\end{tabular}


at $5^{\prime}$ end, and TIM-1-reverse containing XhoI restriction site at $5^{\prime}$ end (Table 1). The PCR program started with 1 cycle at $95^{\circ} \mathrm{C}$ for 4 min, continued by 30 cycles at $95^{\circ} \mathrm{C}$ for $30 \mathrm{sec}, 58^{\circ} \mathrm{C}$ for $30 \mathrm{~s}$ and $72^{\circ} \mathrm{C}$ for $2 \mathrm{~min}$ and $40 \mathrm{~s}$, and ended with 1 cycle at $72^{\circ} \mathrm{C}$ for $10 \mathrm{~min}$ in a thermo cycler (Bio-Rad Laboratory, CA, USA). PCR products were electrophoresed on $1 \%(\mathrm{w} / \mathrm{v})$ agarose and purified using Gel Purification kit (Bioneer Inc., Seoul, South Korea).

\subsection{Cloning of TIM-1 cDNA}

The pcDNA ${ }^{\mathrm{TM}}$ 3.1/Hygro $(+)\left(100 \mathrm{ng}^{-\mathrm{mL}^{-1}}\right)$ (Pasteur Institute, Iran) and TIM-1 amplicons (120 ng. $\left.\mu \mathrm{L}^{-1}\right)$ were separately digested with $\mathrm{XhoI}$ and NheI enzymes (Thermo Fisher Scientific, Inc., MA, USA) according to the manufacturer's instruction. The digestion products (backbone of pcDNA ${ }^{\mathrm{TM}} 3.1$ /Hygro $(+)$ and TIM-1 PCR product) were electrophoresed on $1 \%$ agarose and gel purified. Linearized pcDNA ${ }^{\mathrm{TM}} 3.1 /$ Hygro $(+)$ and TIM-1 were ligated using T4 DNA ligase enzyme (Thermo Fisher Scientific, Inc., MA, USA) according to the manufacturer's instruction. Ligation product was transformed into chemically competent $E$. coli TOP $10 \quad \mathrm{~F}^{\prime}$ using heat shock method (17). The pcDNA $^{\mathrm{TM}} 3.1$ /Hygro $(+)$ contains ampicillin resistance gene, therefore, E. coli TOP $10 \mathrm{~F}^{\prime}$ bacteria could growth in LB culture medium with ampicillin as a selection marker.

To confirm the transfected clones, DNA sequencing was performed using a specific primer: pcDNA forward and reverse (Table 1).

\subsection{Linearization of $p c D N A / T I M-1$}

The pcDNA/TIM-1 plasmid was extracted with plasmid extraction kit (SolGent Co., Ltd., Deajaon, Korea). The extracted pcDNA/TIM-1 was linearized using $B g l$ II enzyme (Thermo Fisher Scientific, Inc., MA, USA) according to the manufacturer's instruction. After electrophoresis of the product on $1 \%$ agarose, the linear plasmid was gel purified.

\subsection{Transfection}

Transfection was performed using TurboFect reagent (Thermo Fisher Scientific, Inc., MA, USA) based on the provided protocol. Prior transfection (24 $\mathrm{h}$ earlier), $1 \times 10^{6}$ HEK $293 \mathrm{~T}$ cells were sub-cultured in two culture flasks so that confluency of the cells on the time of transfection was $60-70 \%$. The linear pcDNA/TIM-1 plasmid $(7.5 \mu \mathrm{g})$ were added to $750 \mu \mathrm{L}$ serum free-DMEM medium, suspended by pipetting, and incubated for $2 \mathrm{~min}$. About $15 \mu \mathrm{L}$ of TurboFect reagent was added to the plasmid suspension and incubated for $15-20 \mathrm{~min}$ at $22^{\circ} \mathrm{C}$. The content of the tube was added to the cell culture flask drop-wise, mixed by swirling and incubated at $37^{\circ} \mathrm{C}$ overnight. In parallel, HEK 293T cells were transfected by linear pcDNA devoid of TIM-1 cDNA as control (mock transfection). On the next day, culture medium was refreshed. Following transfection, the cells were treated with 175 $\mu \mathrm{g} . \mathrm{mL}^{-1}$ hygromycin at day 3 (Roche Diagnostics, Indianapolis, IN, USA) to select the transfected cells.

\subsection{Polymerase Chain Reaction (PCR) on HEK $293 T$ Genomic DNA}

To confirm the integration of linear pcDNA/TIM-1 into genome of HEK 293T cells, one month after transfection, genomic DNA of the transfected and un-transfected cells were extracted by DNA extraction kit (Genetbio, Deajaon, Korea) according to the manufacturer's instruction. PCR with pcDNA forward and reverse primers (Table 1) was carried out. The PCR program was started with 1 cycle at $94^{\circ} \mathrm{C}$ for $3 \mathrm{~min}$, continued by 30 cycles at $94^{\circ} \mathrm{C}$ for $30 \mathrm{sec}, 58^{\circ} \mathrm{C}$ for 30 sec and $72^{\circ} \mathrm{C}$ for $1 \mathrm{~min}$ and $30 \mathrm{sec}$, and ended with 1 cycle at $72^{\circ} \mathrm{C}$ for $10 \mathrm{~min}$ in a thermo cycler (Bio-Rad Laboratory). Genomic DNA of un-transfected HEK 293 T cells was used as the negative control. PCR products of the control and the positive samples were analyzed by electrophoresis on $1 \%$ agarose gel. Expression of human TIM-1 in HEK 293T cell line was examined by flow cytometry and real-time quantitative PCR methods.

\subsection{Flow Cytometry}

Transfected and control cells were placed in 2 distinct flow cytometry tubes (suspension of $1 \times 10^{6}$ cells $/ 200 \mu \mathrm{L}$ medium in each tube), 30 days following transfection. The cells were stained with $1 \mu \mathrm{L}$ PE conjugated monoclonal anti-TIM-1 antibody (Biolegend, Inc., CA, USA), and with appropriate isotype control antibody (Biolegend, UK), separately. Cells were evaluated using FACS Callibour flow cytometry (BD bioscience, NJ, USA). The flow cytometric data were analysed by Cell quest pro software (IBM, CA, USA).

\subsection{Real-Time Quantitative PCR}

Total RNA of selected cells was isolated and cDNA was synthesized as described above. Primers was designed, RTIM forwardand reverse, and $\beta$-actin-forward and reverse (Table 1). Real-time PCR was performed in a total volume of $20 \mu \mathrm{L}$ in the StepOnePlus $^{\mathrm{TM}}$ real-time PCR system (AB Applied 
Biosystems, CA, USA) using SYBR ${ }^{\circledR}$ Premix Ex Taq (Takara Bio Inc., Otsu, Shiga, Japan) with the following program: 1 cycle $95^{\circ} \mathrm{C}$ for $10 \mathrm{~min}$, continued by 40 cycles at $95^{\circ} \mathrm{C}$ for $15 \mathrm{sec}$ and $60^{\circ} \mathrm{C}$ for $1 \mathrm{~min}$. Data analysis was performed using $2^{-\Delta \Delta \mathrm{Ct}}$ method (18). The results were normalized against $\beta$-actin expression level as a reference gene (19). All the reactions were performed in triplicate.

\subsection{Statistical Analyses}

The results were analyzed by SPSS 20 (Chicago, IL, USA) software. Mann-Withney U nonparametric test used to compare the results of groups. All the $\mathrm{qPCR}$ results were reported as Mean $\pm \mathrm{SD}$ (standard deviation) and mean was obtained from three identical repeats of each test.

\section{Results}

\subsection{Amplifying TIM-1 cDNA}

For the purpose of producing a human TIM-1 expressing cell line, we needed the human TIM-1 encoding cDNA. TIM-1 molecule expresses on T helper cells, $\mathrm{B}$ cells, mast cells and macrophages. Therefore, PBMC

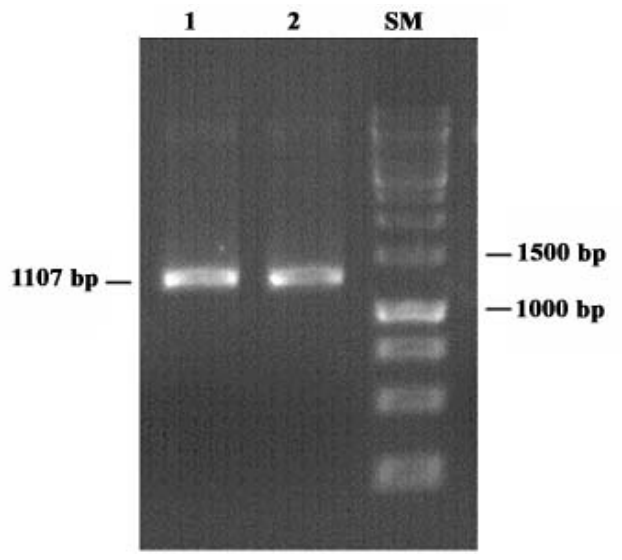

Figure 1. Amplification of specific band for human TIM-1 cDNA using Pfu DNA polymerase. Lane 1 and 2, TIM-1 fragments with size of $1107 \mathrm{bp}$. Lane SM, DNA size marker $(1 \mathrm{~kb})$

could be an appropriate source for this purpose. After amplification of TIM-1 cDNA with specific primers bearing NheI and XhoI specific restriction sites, agarose gel electrophoresis of PCR product demonstrated a 1107 bp band (1095 bp for TIM-1 cDNA and 12 bp for two restriction sites) (Figure 1).

\section{Homo sapiens hepatitis A virus cellular receptor 1 (HVACR1), transcript variant 1, mRNA Sequence ID: ref[NM 012206.3] Length: 1713 Number of Matches: 1}

\begin{tabular}{|c|c|c|c|c|c|c|c|}
\hline \multirow{2}{*}{\multicolumn{2}{|c|}{$\begin{array}{l}\text { Range 1: } 299 \text { to } 13 \\
\text { Score } \\
2023 \text { bits (1095) }\end{array}$}} & \multicolumn{3}{|c|}{ GenBank Graphics } & \multicolumn{3}{|c|}{$\nabla$ Next Match $\Delta$ Previous Match } \\
\hline & & & $\begin{array}{l}\text { Expect } \\
0.0\end{array}$ & $\begin{array}{l}\text { Identities } \\
1095 / 1095(100 \%)\end{array}$ & $\begin{array}{l}\text { Gaps } \\
0 / 1095(0 \%)\end{array}$ & $\begin{array}{l}\text { Stran } \\
\text { Plus/ }\end{array}$ & \\
\hline Query & $\mathbf{1}$ & \multicolumn{5}{|c|}{ 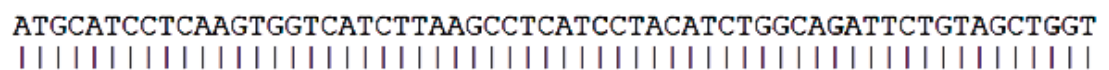 } & 60 \\
\hline Sbjet & 299 & \multicolumn{5}{|c|}{ ATGCATCCTCAAGTGGTCATCTTAAGCCTCATCCTACATCTGGCAGATTCTGTAGCTGGT } & 358 \\
\hline Query & 61 & \multirow{2}{*}{\multicolumn{5}{|c|}{$\begin{array}{l}\text { TCTGTAAAGGTTGGTGGAGAGGCAGGTCCATCTGTCACACTACCCTGCCACTACAGTGGA } \\
\text { |||||||||||||||||||||||||||||||||||||||||||||||||||||||||||||||||||||||||||||| } \\
\text { TCTGTAAAGGTTGGTGGAGAGGCAGGTCCATCTGTCACACTACCCTGCCACTACAGTGGA }\end{array}$}} & 120 \\
\hline Sbjet & 359 & & & & & & 418 \\
\hline Query & 121 & \multirow{2}{*}{\multicolumn{5}{|c|}{ 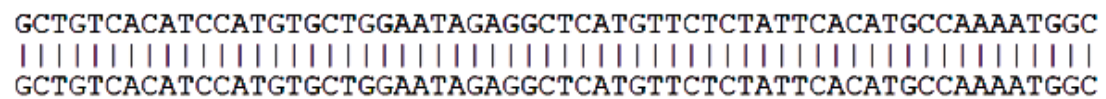 }} & 180 \\
\hline Sbjet & 419 & & & & & & 478 \\
\hline
\end{tabular}

\begin{tabular}{|c|c|c|}
\hline $\begin{array}{l}\text { Query } \\
\text { Sbjet }\end{array}$ & 1021 & 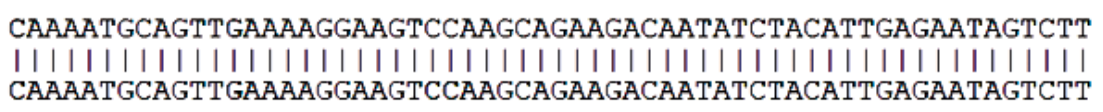 \\
\hline Query & 1081 & $\begin{array}{l}\text { TATGCCACGGACTAA } \\
|||||||||||||| \mid\end{array}$ \\
\hline Sbjet & 1379 & TATGCCACGGACTAA \\
\hline
\end{tabular}

Figure 2. Nucleotide sequence alignment of cloned TIM-1at NCBI. Cloned TIM-1 sequence showed complete identity with human TIM-1 reference sequence. Only 5' to $3^{\prime}$ ends of sequence have been briefly shown 


\subsection{Sequencing of $p c D N A / T I M-1$}

After transformation of pcDNA/TIM-1 construction into competent $E$. coli TOP 10 F' bacteria, to confirm cloning of pcDNA/TIM-1 construction, DNA sequencing proved the presence of similar sequence with human TIM-1 reference sequence in the recombinant plasmid (Figure 2).

\subsection{Expression of Human TIM-1 Protein}

Following transfection of HEK 293T cells with liner pcDNA/TIM-1, to assess integration of linear pcDNA/TIM-1 into the genome of HEK 293T cells, PCR was performed and gel electrophoresis demonstrated the presence of pcDNA/TIM-1 in HEK 293T genomic DNA (band of $1240 \mathrm{bp}$ ) (Figure 3). The results of flow cytometry showed $88.15 \%$ of transfected cells expressed TIM-1 protein on their own surfaces. On the other hand, surface staining of un-transfected and mock transfection cells have no expression of TIM-1(1.72 and 1.59\%, respectively) (Figure 4). Real-time PCR results were in parallel with flow cytometry results revealed that levels of TIM-1 expression increased up to 195-fold $(\mathrm{p}<0.05)$ (Figure 5).

\section{Discussion}

Considering the role of the TIM-1 in development of autoimmune diseases and allergy, regulation of

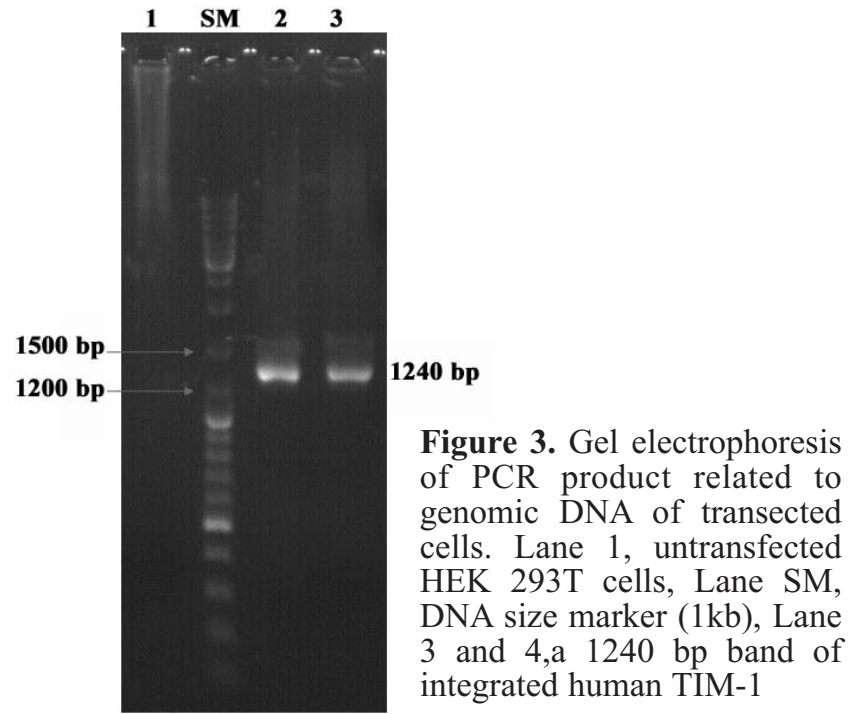

rolling of T cell subsets particularly Th1 and Th17 cell homing into the central nervous system (CNS), homeostasis of tumor microenvironment and receptor for virus entrance into host cells (2, 8-10), TIM-1 could be considered as a target for therapy of $\mathrm{T}$ cell-mediated diseases and virus infection using its specific monoclonal antibody, nanobody or aptamer $(7,15)$.

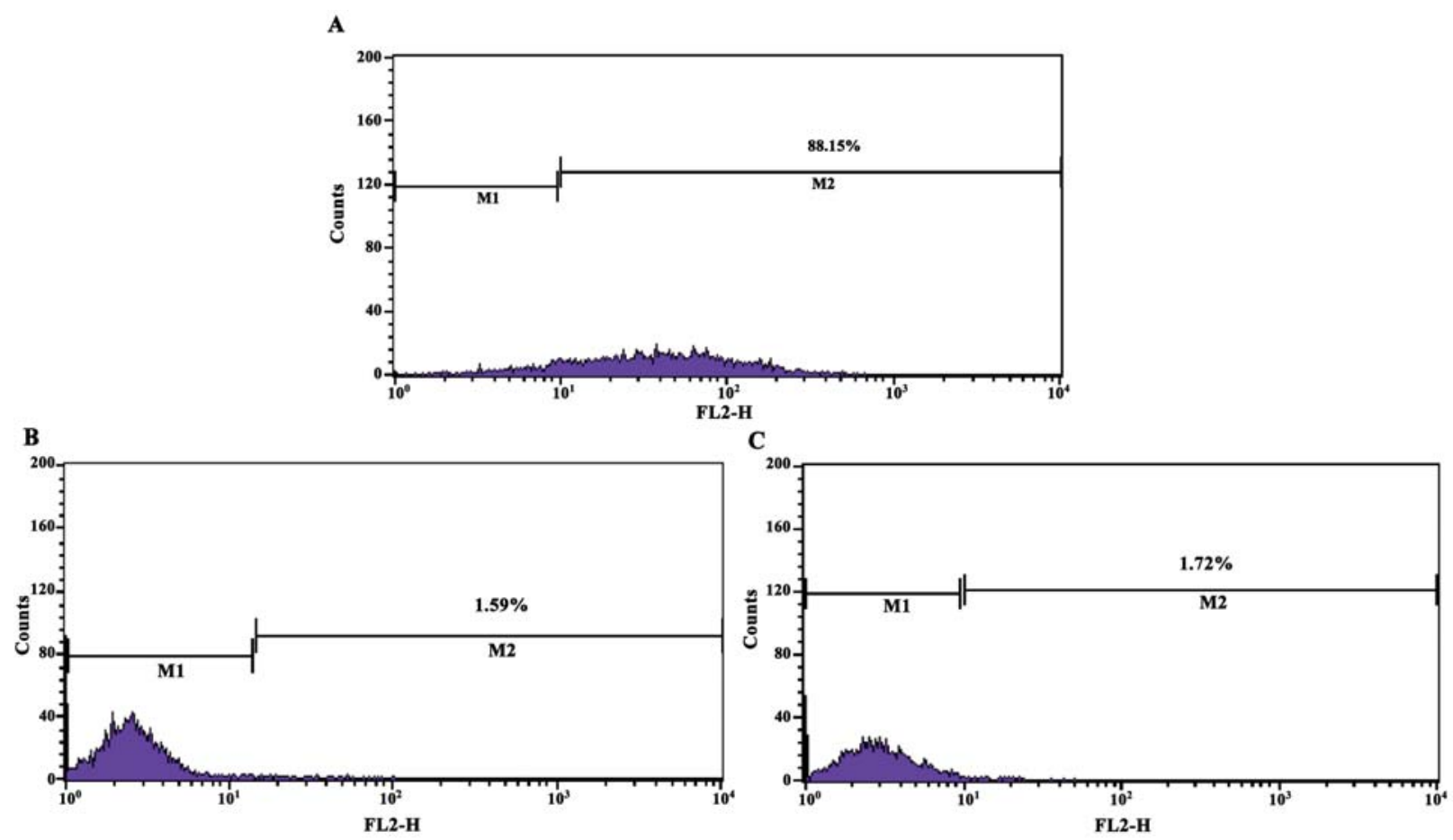

Figure 4. Flow cytometric analysis. Transfected cells displayed significantly positive signal, whereas mock transfected and untransfected cells showed no positive signal. A: pcDNA/TIM-1 transfected HEK 293T. B: Mock transfected HEK 293T. C: untransfected HEK 293T. FL2: Anti human TIM-1-PE 


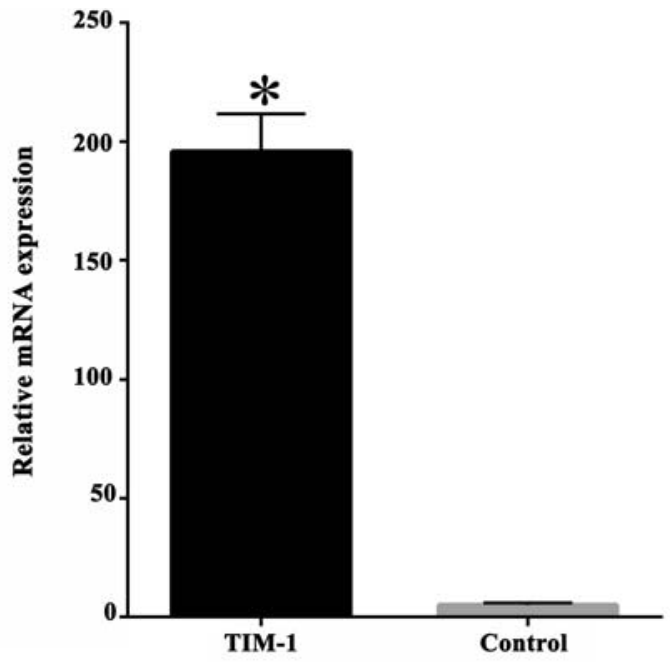

Figure 5. Real-time quantitative PCR analysis. TIM-1 column represents human TIM-1 mRNA expression level in transfected cells with linearized pcDNA/TIM-1 and control column represents human TIM-1 mRNA expression in untransfecetd ones. The results are represented as mean $\pm \mathrm{SD}$ $(\mathrm{n}=3) ;{ }^{*} \mathrm{p}<0.05$ versus control cells

Several anti-TIM-1 monoclonal antibodies have been used in treatment of experimental autoimmune diseases, allergy and viral infections. Xiao et al. (20) using anti-TIM-1 antibodies showed that these antibodies could have a dual function: inhibiting and increasing of $\mathrm{T}$ cell responses in autoimmune encephalomyelitis. The results of Encinas et al. (21) research indicated that anti-TIM-1 antibody can decrease Th2 responses in a mouse model of asthma. Study of Soo Hoo et al. (22) showed that TIM-1 antibodies caused induction of cellular proliferation and IFN- $\gamma$ production against influenza virus infection.

The cells over-expressing a certain molecule are an appropriate model as target for the production of monoclonal antibodies, nanobodies and selection process of aptamers. Eukaryotic cells provide a suitable source for recombinant protein production with accurate folding and proper post translational modifications. Consistent with previous data, the HEK 293T cells are suitable source for this aim (23-26).

Kondratowicz et al. (13) have reported transient transfection of a TIM-1 expressing plasmid into HEK $293 \mathrm{~T}$ cells have been resulted in TIM-1 surface expression in about $20 \%$ of the population. Also Moller-Tank et al. (14) have reached to 70\% TIM-1 surface expression; whereas our results showed $88.15 \%$ of cells have stably expressed TIM-1 protein. This very high expression was obtained by
pcDNA $^{\mathrm{TM}}$ 3.1/Hygro $(+)$ vector, which contain cytomegalovirus promoter. Hence, these cells, as an available "cell display" source, could be used for production of specific molecules against TIM-1.

\section{Funding/Support}

This work is financially supported by a grant (no. 9299) from Immunology Research Center, Tabriz University of Medical Sciences.

\section{References}

1. Kane LP. T Cell Ig and mucin domain proteins and immunity. $J$ Immunol. 2010;184:2743-2749. DOI: 10.4049/jimmunol.0902937

2. Freeman GJ, Casasnovas JM, Umetsu DT, DeKruyff RH. TIM genes: a family of cell surface phosphatidylserine receptors that regulate innate and adaptive immunity. Immunol Rev. 2010;235:172-189. DOI: 10.1111/j.0105-2896.2010.00903.x

3. Rennert PD. Novel roles for TIM-1 in immunity and infection. Immunol Lett. 2011;141:28-35. DOI: 10.1016/j.imlet.2011. 08.003

4. McIntire JJ, Umetsu SE, Akbari O, Potter M, Kuchroo VK, Barsh GS, Freeman GJ, Umetsu DT, DeKruyff RH. Identification of Tapr (an airway hyperreactivity regulatory locus) and the linked TIM gene family. Nat Immunol. 2001;2:1109-1116.

5. McIntire JJ, Umetsu DT, De Kruyff RH. TIM-1, a novel allergy and asthma susceptibility gene. Springer Semin Immunopathol. 2004;25:335-348. DOI: 10.1007/s00281-0030141-3

6. Rodriguez-Manzanet R, DeKruyff RH, Kuchroo VK, Umetsu DT. The costimulatory role of TIM molecules. Immunol Rev. 2009;229:259-270. DOI: 10.1111/j.1600-065X.2009.00772.x

7. Kuchroo VK, Umetsu DT, DeKruyff RH and Freeman GJ. The TIM gene family: emerging roles in immunity and disease. Nat Rev Immunol. 2003;3:454-462. DOI: 10.1038/nri1111

8. Meyers JH, Sabatos CA, Chakravarti S, Kuchroo VK. The TIM gene family regulates autoimmune and allergic diseases. Trends Mol Med. 2005;11:362-369. DOI: http://dx.doi.org/ 10.1016/j.molmed.2005.06.008

9. Angiari S, Donnarumma T, Rossi B, Dusi S, Pietronigro E, Zenaro E, Della Bianca V, Toffali L, Piacentino G, Budui S, Rennert P, Xiao S, Laudanna C, Casasnovas JM, Kuchroo VK, Constantin G. TIM-1 glycoprotein binds the adhesion receptor P-selectin and mediates $\mathrm{T}$ cell trafficking during inflammation and autoimmunity. Immunity. 2014;40:542-553. DOI: 10.1016/j.immuni.2014.03.004

10. Jemielity S, Wang JJ, Chan YK, Ahmed AA, Li W, Monahan $\mathrm{S}, \mathrm{Bu}$ X, Farzan M, Freeman GJ, Umetsu DT, Dekruyff RH, Choe H. TIM-family proteins promote infection of multiple enveloped viruses through virion-associated phosphatidylserine. PLoS Pathog. 2013;9:e1003232. DOI: 10.1371/journal. ppat. 1003232

11. Lee HH, Meyer EH, Goya S, Pichavant M, Kim HY, Bu X, Umetsu SE, Jones JC, Savage PB, Iwakura Y, Casasnovas JM, Kaplan G, Freeman GJ, DeKruyff RH, Umetsu DT. Apoptotic 
cells activate NKT cells through T Cell Ig-Like Mucin-Like-1 resulting in airway hyperreactivity. $J$ Immunol. 2010;185:5225-5235. DOI: 10.4049/jimmunol.1001116

12. Perera-Lecoin M, Meertens L, Carnec X, Amara A. Flavivirus entry receptors: An update. Viruses 2014;6:69-88. DOI: 10.3390/v6010069

13. Kondratowicz AS, Lennemann NJ, Sinn PL, Davey RA, Hunt CL, Moller-Tank S, Meyerholz DK, Rennert P, Mullins RF, Brindley M, Sandersfeld LM, Quinn K, Weller M, McCray PB Jr, Chiorini J, Maury W. T-cell immunoglobulin and mucin domain 1 (TIM-1) is a receptor for Zaire Ebolavirus and Lake Victoria Marburgvirus. Proc Natl Acad Sci USA. 2011;108:8426-8431. DOI: 10.1073/pnas.1019030108

14. Moller-Tank S, Kondratowicz AS, Davey RA, Rennert PD, Maury W. Role of the phosphatidylserine receptor TIM-1 in enveloped-virus entry. J Virol. 2013;87:8327-8341. DOI: 10.1128/JVI.01025-13

15. Moller-Tank S, Albritton LM, Rennert PD, Maury W. Characterizing functional domains for TIM-mediated enveloped virus entry. J Virol. 2014;88:6702-6713. DOI: 10.1128/JVI.00300-14

16. Ruffell B, DeNardo DG, Affara NI, Coussens M. Lymphocytes in cancer development: polarization towards pro-tumor immunity. Cytokine Growth Factor Rev. 2010;21:3-10. DOI: 10.1016/j.cytogfr.2009.11.002

17. Froger A, Hall JE. Transformation of plasmid DNA into $E$. coli using the heat shock method. J Vis Exp. 2007;6:253. DOI: $10.3791 / 253$

18. Livak KJ, Schmittgen TD. Analysis of relative gene expression data using real-time quantitative PCR and the 2 (-Delta Delta C (T)) Method. Methods 2001;25:402-408.

19. Jiwaji M, Daly R, Pansare K, McLean P, Yang J, Kolch W, Pitt AR. The Renilla luciferase gene as a reference gene for normalization of gene expression in transiently transfected cells. BMC Mol Biol. 2010;11:103. DOI: 10.1186/1471-2199-11103

20. Xiao S, Najafian N, Reddy J, Albin M, Zhu C, Jensen E, Imitola J, Korn T, Anderson AC, Zhang Z, Gutierrez C, Moll T, Sobel RA, Umetsu DT, Yagita H, Akiba H, Strom T, Sayegh MH, DeKruyff RH, Khoury SJ, Kuchroo VK. Differential engagement of Tim-1 during activation can positively or negatively costimulate $\mathrm{T}$ cell expansion and effector function. J Exp Med. 2007;204:1691-1702. DOI: 10.1084/ jem.20062498

21. Encinas JA, Janssen EM, Weiner DB, Calarota SA, Nieto D, Moll T, Carlo DJ, Moss RB. Anti-T-cell Ig and mucin domaincontaining protein 1 antibody decreases TH2 airway inflammation in a mouse model of asthma. J Allergy Clin Immunol. 2005;116:1343-1349. DOI: http://dx.doi.org/10.1016/j.jaci. 2005.08 .031

22. Soo Hoo W, Jensen ER, Saadat A, Nieto D, Moss RB, Carlo DJ, Moll T. Vaccination with cell immunoglobulin mucin-1 antibodies and inactivated influenza enhances vaccine-specific lymphocyte proliferation, interferong production and crossstrain reactivity. Clin Exp Immunol. 2006;145:123-129.

23. Zhu J. Mammalian cell protein expression for biopharmaceutical production. Biotechnol Adv. 2012;30:1158-1170. DOI: 10.1016/j.biotechadv.2011.08.022
24. Thomas P, Smart TG. HEK293 cell line: a vehicle for the expression of recombinant proteins. J Pharmacol Toxicol Methods. 2005;51:187-200.

25. Lennon VA, Kryzer TJ, Pittock SJ, Verkman AS, Hinson SR. IgG marker of optic-spinal multiple sclerosis binds to the aquaporin-4 water channel. J Exp Med. 2005;202:473-477. DOI: $10.1084 /$ jem.20050304

26. Estacion M, Sinkins WG, Jones SW, Applegate MA, Schilling WP. Human TRPC6 expressed in HEK 293 cells forms nonselective cation channels with limited $\mathrm{Ca}^{2+}$ permeability. $J$ Physiol. 2006;572:359-377. 